\title{
1 Biomarkers for the assessment of exposure to fluoride in children
}

2 Authors: Oladipo S Idowu ${ }^{1}$, Ralph M Duckworth ${ }^{1}$, Ruth AValentine ${ }^{2}$, Fatemeh V Zohoori 1,*

3

$4 \quad{ }^{1}$ School of Health and Social Care, Teesside University, Middlesbrough Tees Valley, TS1 3BA UK.

$5 \quad{ }^{2}$ School of Dental Sciences, Newcastle University, Framlington Place, Newcastle Upon Tyne, NE2 6 4BW, UK.

7

8 Short title: Biomarkers of fluoride exposure

9

$10 *$ Corresponding author:

11 Professor FV Zohoori

12 School of Health and Social Care

13 Teesside University

14 TS1 3BA, UK

15 e-mail: v.zohoori@tees.ac.uk

16

17 Keywords: Toenail, fingernail, hair, plasma, urine 


\section{ABSTRACT}

2 Due to practical difficulties in quantifying fluoride exposure, the ability of various biomarkers to predict

3 it has been investigated previously. However, the results are inadequate for validation of their 4 application and usefulness. This study aimed to investigate the association between 5 contemporary/recent biomarkers of fluoride exposure and total daily fluoride intake (TDFI) of children 6 with large differences in fluoride exposure through drinking water. TDFI was assessed in 61 healthy 4 7 to 5 years old children who provided at least one biomarker sample; 32 lived in a low-fluoride area $8(0.04 \mathrm{mgF} / \mathrm{L})$ and 29 lived in a high-fluoride area $(3.05 \mathrm{mgF} / \mathrm{L})$. Validated questionnaires were 9 administered to evaluate fluoride intake from diets (including water) and toothpaste ingestion. Daily urinary fluoride excretion (UFE) as well as fluoride concentrations in plasma, fasting whole saliva, hair and nails (toenails/fingernails) were evaluated and related to total fluoride exposure. TDFI, UFE and fluoride concentration of biomarkers were statistically significantly higher in the high-fluoride area than in the low-fluoride area. There was a strong statistically significant positive correlation between TDFI and: UFE $(\rho=0.756, \mathrm{p}<0.001)$; plasma fluoride concentration $(\rho=0.770, \mathrm{p}<0.001)$; toenail fluoride concentration $(\rho=0.604, \mathrm{p}<0.001)$. The statistically significant positive correlation between TDFI and fingernail fluoride concentration $(\rho=470, \mathrm{p}<0.001)$ as well as between TDFI and fasting whole saliva fluoride concentration ( $\rho=0.453, \mathrm{p}=0.001)$ was moderate, whereas it was weak between TDFI and hair fluoride concentration $(\rho=0.306, \mathrm{p}=0.027$ ). In conclusion, the current study confirmed the suitability of $24 \mathrm{~h}$ urine samples for estimating F exposure in children. The strong correlations between TDFI and F in plasma and toenails also suggest these biomarkers may be considered for health risk assessments of fluoride in children who are susceptible to development of dental fluorosis. 
2 Dental caries still remains the most predominant preventable health condition across the globe [GBD 32016 Risk Factors Collaborator, 2017]. Due to the well-recognised role of fluoride (F) in prevention 4 and control of dental caries, it has been added to water, milk, salt and dental products in many countries. 5 However, studies from both fluoridated and non-fluoridated communities have shown an increase in the prevalence of dental fluorosis over time [Harding and O'Mullane, 2013; Khan et al., 2005]. The caries-preventive effects of $\mathrm{F}$ are primarily topical, whereas the prevalence and severity of dental fluorosis are a reflection of chronic excessive ingestion of $\mathrm{F}$ during crucial periods of tooth development [Hellwig and Lennon, 2004]. Therefore, regular monitoring of systemic F exposure is crucial to address any potential adverse health effects of $\mathrm{F}$.

Sources of $\mathrm{F}$ exposure are becoming more diverse, with diet (including water) and unintentional ingestion of dental products as the most important. Due to practical difficulties in quantifying $\mathrm{F}$ exposure, from all sources in individuals, F biomarkers have been suggested as alternative approaches to monitor deficient or excessive intakes of bioavailable F [World Health Organization, 1994].

Ingested F is rapidly distributed throughout the body: $\mathrm{F}$ in plasma can be measured within 10 minutes of ingestion and reaches a peak within 30-60 min [Buzalaf and Whitford, 2011]. Almost 60\% of the absorbed $\mathrm{F}$ by adults and $45 \%$ by children is excreted in urine within 24 hours of ingestion. Most of the retained $\mathrm{F}$ in the body is bound to calcified tissues, whereas $<1 \%$ is found in soft tissues [Buzalaf and Whitford, 2011]. Although the F concentrations of specialised body fluids are different from those in plasma, they change concurrently and in proportion to those in plasma [Buzalaf and Whitford, 2011].

F concentrations in plasma, saliva, milk, sweat and urine have been suggested as biological markers for assessment of present or very recent exposure to F [Buzalaf et al., 2012; Buzalaf et al., 2011; RuggGunn et al., 2011]. The F content of nails and hair reflects intake over longer periods of time (recent biomarkers), whilst $\mathrm{F}$ in bone and teeth are regarded as historic $\mathrm{F}$ biomarkers [Pessan and Buzalaf, 2011].

Among the suggested F biomarkers, urine is currently regarded as the most useful biomarker of recent $\mathrm{F}$ exposure at a community level, which can rapidly detect any variations in $\mathrm{F}$ exposure [Martins et al., 2011], with established normal values for 24h urinary F excretion in children [World Health Organization, 2014].

Due to the challenges in collection of $24 \mathrm{~h}$ urine samples, particularly in children, several studies attempted to investigate the ability of other biomarkers to predict $\mathrm{F}$ exposure [Boros et al., 2001; Buzalaf et al., 2012; Buzalaf et al., 2011; Czarnowski and Krechniak, 1990; Joshi and Ajithkrishnan, 2018; 
1 Kono et al., 1993; Levy et al., 2004; Lima-Arsati et al., 2010; Linhares et al., 2016; Oliveby et al., 1989;

2 Schamschula et al., 1985; Whitford, 2005]. However, their results are inadequate to make any proposals

3 on the application and usefulness of plasma, nails and hair as biomarkers of $\mathrm{F}$ exposure. The above

4 literature shows no robust consensus that they would be reliable indicators of $\mathrm{F}$ exposure in different

5 age groups and populations.

6 More studies are needed to explore the best $\mathrm{F}$ biomarker and quantify normal $\mathrm{F}$ concentration of the 7 biomarkers for populations exposed to a wide range of $\mathrm{F}$, from very low water $\mathrm{F}$ areas to endemic $\mathrm{F}$ 8 areas. This study therefore aimed to investigate the association between total $\mathrm{F}$ intake and contemporary/recent biological markers of exposure to $\mathrm{F}$ in children with large differences in $\mathrm{F}$ exposure through water. The objectives were to assess the concentrations of $\mathrm{F}$ in urine, plasma, hair and finger- and toe-nail clippings.

\section{Materials and Methods}

North Central Nigeria, where the natural F concentration in groundwater varies considerably (Lar et al. 2014), provided a suitable study location.

The study was approved by the School of Health and Social Care Ethics Committee, Teesside University (Study number 065/15) and the Jos University Teaching Hospital Ethics Committee, JUTH, Plateau State, Nigeria (JUTH/DCS/ADM/127/XIX/6408).

Healthy children aged 4-5 years from a low-F water area (LFA; Bokkos Local Government Area (LGA)) and a high-F water area (HFA; Langtang North LGA), living in their residency area since birth, were invited to participate in this cross-sectional observational study. Written informed consent was obtained from the parents of participants who volunteered to take part.

\section{Data and sample collection}

Two visits were arranged with the participants when data and samples were collected. During Visit 1, the weight of each child was measured without shoes and jacket to the nearest $0.1 \mathrm{~kg}$ using a portable digital balance (Seca 803, Seca, Germany). The parents were interviewed to collect demographic information and their children's oral hygiene habits, including the type of toothpaste used regularly (if their children brushed) and frequency of brushing per day, using a validated questionnaire [Ibiyemi et al., 2018; Levy and Zarei-M, 1991]. A validated food frequency questionnaire (FFQ) [Ibiyemi et al., 2018; Levy and Zarei-M, 1991] was also administered to estimate F intake from diet. To confirm the F concentration of each child's home water supply, a sample was collected and analysed for F. Samples 
of toothpaste brands used by the children as well as the most frequently consumed food and drinks identified from the FFQ were obtained and analysed for F content. A small sample of hair of the child were cut as close to the scalp as possible from the back of the head. Parents were instructed to clean their child's hands and foot before clipping the nails from all digits. They were also asked to store fingernails and toenails in separate zip-lock bags. Children with very short nails were instructed to let their nails to grow for 1-2 weeks prior to clipping.

Parents were provided with containers and bottles as well as written and verbal instructions for collecting samples of food, drinks, $24 \mathrm{~h}$ urine and finger- and toe-nail clippings. The participants were given an appointment for the second visit and were asked not to eat or drink anything or use toothpaste/mouth rinses for at least 4 hours before the visit. At Visit 2, unstimulated whole saliva was collected by asking the participants to drool into plastic vials. A 5-mL blood sample was collected from each child by a qualified nurse. Samples of food, drinks, 24h urine and nail clippings collected by parents and the completed FFQ were also picked up.

\section{Sample preparation and analysis}

Urine samples collected over the $24 \mathrm{~h}$ period were pooled for each participant, and the total volume was measured. Saliva samples were centrifuged at $1000 \mathrm{rpm}$ (MSE Harrier 18/80, UK) for 2 min to separate any food debris [Martínez-Mier et al., 2011]. Each blood sample was centrifuged for 10 min at 1500 rpm and the plasma collected. Nail samples from each participant (finger- and toe-nails, separately) were weighed, and then surface contamination from the nail clippings was removed by sonication in distilled water for $15 \mathrm{~min}$ [Whitford, 2005]. The cleaned samples were dried at $95^{\circ} \mathrm{C}$ and weighed again. Food samples were weighed and then homogenised using an industrial blender (Cookwork BL9292, UK).

Water and urine samples were analysed directly using a F ion selective electrode (ISE, 720A series; Orion Research Inc., Boston, MA, USA) after addition of TISAB III [Martínez-Mier et al., 2011]. Food, toothpaste, plasma, whole saliva, hair and nail samples were analysed after overnight hexamethyldisiloxane-acid diffusion [Martínez-Mier et al., 2011].

To examine the reliability of the F analytical methods, $10 \%$ of the samples were re-analysed. The results confirmed no statistically significant differences in the means between test and retest for all the samples.

\section{Data preparation}

The completeness of $24 \mathrm{~h}$ urine samples was checked by comparing urinary flow rate $(\mathrm{mL} / \mathrm{h})$ with the World Health Organization [World Health Organization, 2014] reference ranges for <6-year-olds (5- 
$1 \quad 160 \mathrm{~mL} / \mathrm{h}$ ). Children with a urine flow rate outside this range were excluded from data analysis. Daily

2 urinary $\mathrm{F}$ excretion (DUFE; $\mathrm{mg} / \mathrm{d}$ ) was estimated by multiplying the $24 \mathrm{~h}$ urine volume by the $\mathrm{F}$

3 concentration of the urine sample.

$4 \quad$ Each child's daily dietary F intake was estimated by multiplying the F concentration $(\mathrm{mg} / \mathrm{kg})$ of each

5 food and drink by the corresponding amount $(\mathrm{kg})$ consumed per day and then summing these values to

6 derive a total in $\mathrm{mg} / \mathrm{d}$ and on a body weight basis $(\mathrm{mg} / \mathrm{kg} \mathrm{bw} / \mathrm{d}) . \mathrm{F}$ ingestion from toothpaste (mg/d)

7 was estimated by multiplying the pictorially [Levy and Zarei-M, 1991] estimated weight of toothpaste

8 used per brushing ( $\mathrm{mg}$ ) by its F concentration and frequency of use. The obtained value was multiplied

9 by $41 \%$ : the mean $\%$ of toothpaste ingested per tooth brushing session reported among four-year-olds in Iran [Zohouri and Rugg-Gunn, 2000] and the UK [Zohoori et al., 2012]. Total daily F intake (TDFI; $\mathrm{mg}$ /day) was estimated from diet and ingestion from toothpaste by summing up F intake from these two sources.

TDFI and DUFE were also calculated based on body weight $(\mathrm{mg} / \mathrm{kgbw} / \mathrm{d})$ by dividing these values (mg/d) by body weight $(\mathrm{kg})$.

\section{Statistical analysis}

Sample size: A power analysis was undertaken to estimate appropriate sample size based on previous studies [Levy et al., 2004; Schamschula et al., 1985], which showed a highly significant difference in the level of $\mathrm{F}$ in the biomarkers with increasing water $\mathrm{F}$ concentration. It was estimated that 20 children per area would be needed for $90 \%$ power and an assumed statistical significance level $\alpha$ of 0.05 . However, 62 children were invited to allow for drop outs.

The data were analysed descriptively using SPSS version 22. Independent t-tests were used to compare means for each parameter between the LFA and HFA groups. Pearson's correlation coefficient was used to examine the relationships between the various biomarkers and TDFI. The strength of the correlation $(\rho)$ was then evaluated using the following categories [Evan, 1996]: very weak $(0.00-0.19)$, weak $(0.20$ $0.39)$, moderate $(0.40-0.59)$, strong $(0.60-0.79)$ and very strong $(0.80-1.00)$.

\section{Results}

In total, 61 children provided at least one sample; 32 in LFA and 29 in HFA. There was no statistically significant difference in the age and weight of children living in the LFA (4.4y and $16.3 \mathrm{~kg}$ respectively) and HFA (4.4y and $15.7 \mathrm{~kg}$ respectively). The mean (SD) F concentration of the drinking water for the LFA and HFA was 0.04 (0.02) and 3.05 (1.10) $\mathrm{mg} / \mathrm{L}$, respectively. 
1 Of the 61 children who participated in the study: 56 provided complete $24 \mathrm{~h}$ urine, 55 whole saliva, 60

2 plasma, 52 hair, 43 fingernail and 51 toenail samples. Table 1 presents the mean (SD) of TDFI, 24h

3 UFE and F concentrations of the biomarkers. Comparison between the two F water areas indicated no

4 difference in $\mathrm{F}$ intake from toothpaste ingestion, whereas $\mathrm{F}$ intake from diet and TDFI was higher ( $\mathrm{p}<$

5 0.001) in HFA compared with LFA. In addition, 24h UFE and F concentrations of biomarkers were

6 statistically significantly higher in the HFA than in LFA.

7 The linear relationships between the various biomarkers and TDFI are presented in Figures 1 to 4 . There 8 were strong statistically significant positive correlations between TDFI and i) 24h UFE (Figure 1: $9 \rho=0.756, p<0.001$ ); ii) plasma (Figure 2: $\rho=0.770, p<0.001$ ) and iii) toenails (Figure 3: $\rho=0.604$, 10 $\mathrm{p}<0.001$ ). The statistically significant positive correlation between TDFI and fingernails (Figure 3: $\rho=470, \mathrm{p}<0.001$ ) as well as between TDFI and fasting whole saliva (Figure $2: \rho=0.453, \mathrm{p}=0.001$ ) was moderate, whereas it was weak between TDFI and hair (Figure 4: $\rho=0.306, \mathrm{p}=0.027$ ).

\section{Discussion}

The current study quantified the amount of excreted $\mathrm{F}$ in $24 \mathrm{~h}$ urine samples as well as the concentrations of $\mathrm{F}$ in fasting plasma, saliva and nails, and related the findings to the total $\mathrm{F}$ exposure in children. A clear differentiation in F concentration of biomarkers between LFA and HFA was observed in this study which confirms the validity of the methodologies employed. The results show a strong correlation between TDFI and F in 24h urine, plasma and toenails; suggesting their potential as biomarkers of exposure during recent weeks or months. The current study is unique as the correlations between $\mathrm{F}$ exposure and several $\mathrm{F}$ biomarkers were studied, simultaneously, in children exposed to a large range of systemic F from 0.075 to $0.277 \mathrm{mg} / \mathrm{kgbw} / \mathrm{d}$.

The current study used the Iowa Fluoride Study's validated questionnaires [Levy and Zarei-M, 1991], which were previously exploited in Nigerian children [Ibiyemi et al., 2018], to obtain the information on dietary and oral hygiene habits for each individual child. The F exposure was then estimated from data derived from the questionnaires and laboratory $\mathrm{F}$ analysis of collected samples of home tap water and all regularly used food, drink and dental products.

The mean TDFI of all children in HFA $(0.277 \mathrm{mgF} / \mathrm{kgbw} / \mathrm{d})$ was far above the suggested upper limit of F intake of 0.1mg/kgbw/d [Burt, 1992; Zohoori, 2018] which could potentially place a child at greater risk of dental fluorosis. These results clearly show the impact of a high concentration of naturally occurring $\mathrm{F}$ in drinking water (3.05 mg F/L in HFA) on undesirable total $\mathrm{F}$ intake in children. The same trend has also been reported in a recent study [Ibiyemi et al., 2018] in Nigerian 4-year-olds: a TDFI of 
$1 \quad 0.062$ and $0.385 \mathrm{mg} / \mathrm{kgbw} / \mathrm{d}$ for those children receiving water with median F concentrations of 0.06 -

$2 \quad 0.07 \mathrm{ppm}$ and 2-3 ppm, respectively.

3 Early studies reported parallel levels of $\mathrm{F}$ in water and urine in both children and adults [Zipkin et al., 4 1956]. However, the current study found higher concentrations of $F$ in urine than those in water in both 5 areas (Table 1). This finding confirms the diversity of $\mathrm{F}$ sources prevalent today, not only drinking water but mainly diet and unintentional ingestion of dental products. Tea (with a consumption of up to $270 \mathrm{~mL} /$ day and $\mathrm{F}$ concentration of $2.78 \mu \mathrm{g} / \mathrm{mL}$, as reported elsewhere [Idowu, 2018]) was the major source of F intake for this age group of Nigerian children living in the LFA. However, a locally prepared drink from maize (with a consumption of up to $2200 \mathrm{~mL} /$ day and a F concentration of $2.43 \mu \mathrm{g} / \mathrm{mL}$ ) was the main source of F intake for the children in the HFA.

The observed strong correlation between TDFI and 24h UFE in Nigerian children in this study (Figure 1) agrees with the same correlation reported for children younger than 7 years old, consuming a westernised diet [Villa et al., 2010]. These findings suggest that daily F exposure in young children can be predicted from daily urinary $\mathrm{F}$ excretion, regardless of the type of diet (westernised vs nonwesternised). Despite the usefulness of 24h UFE for assessment of F exposure, collection of a sample for a full 24 hours can be quite challenging and inconvenient. Therefore, it is necessary to accurately and reliably identify other biomarkers which can be collected more easily.

A number of recent studies, mainly conducted in adults [Bashash et al., 2018; Bashash et al., 2017; Thomas et al., 2016] used spot urine samples to estimate F exposure and its link with several health outcomes. Although the potential of spot urine samples to predict $\mathrm{F}$ exposure has been examined in young children [Zohoori and Maguire, 2017; Zohouri et al., 2006], its appropriateness to estimate F exposure in adults has not been examined and validate. Therefore, studies with adults are needed to provide more robust evidence on the suitability of spot urine samples for estimation of $F$ exposure in this age group.

The present study found a strong significant correlation between plasma F concentration and TDFI (Figure 2), which is consistent with a number of other human studies that attempted to relate $\mathrm{F}$ concentration in plasma to F intake [Rugg-Gunn et al., 2011]. Plotting the maximum F concentration in plasma after ingestion against the $\mathrm{F}$ dose, reported in 11 studies, showed a direct correlation between them for adults [Rugg-Gunn et al., 2011].

However, no significant correlation between plasma $\mathrm{F}$ concentration and estimated $\mathrm{F}$ intake from diet (0.004 to $0.029 \mathrm{mg} / \mathrm{kgbw} / \mathrm{d}$ ) was reported in 2-6-year-old Brazilian children living in areas with water F concentrations of 0.1-0.8 mg/L [Levy et al., 2004]. The latter study assessed F intake from diet but not the very likely F intake from swallowed fluoridated toothpaste. A study in which total F intake and 
1 plasma $\mathrm{F}$ concentration were estimated for 15-36 months old Mexican children, who consumed 2 fluoridated salt, reported a numerically, but not statistically, higher plasma $\mathrm{F}$ concentration for the 3 children with slightly higher F intake; a plasma F concentration of $0.025 \mu \mathrm{g} / \mathrm{mL}$ with a F intake of 0.20 $\mathrm{mg} / \mathrm{kgbw} / \mathrm{d}$ compared to a plasma $\mathrm{F}$ concentration of 0.016 with mean $\mathrm{F}$ intake of $0.18 \mathrm{mg} / \mathrm{kgbw} / \mathrm{d}$ [Martinez-Mier et al., 2003]. Pharmacokinetic data [Ekstrand et al., 1994] for infants given a F dose of 0.0029 to $0.037 \mathrm{mg} / \mathrm{kgbw}$ also indicated that neither the peak plasma F concentration nor the area under

7 the plasma $F$ concentration curve was related to $F$ intake. The relatively narrow range of $F$ intake taken by infants and children in these previous studies might be the reason for the lack of any correlation found. Plasma F concentration could be influenced by several factors, independent of F exposure, including site of blood collection, acid-base balance, altitude, haematocrit, age and genetic background [Buzalaf and Whitford, 2011]. Therefore, more studies in different age groups and geographical areas, using a standardised protocol (e.g. standardised time and site of blood collection), are needed to investigate the effect of those factors on plasma F concentration.

Despite the observed increase in F concentration in fasting whole saliva with increasing $\mathrm{F}$ intake, the correlation was moderate (Figure 2). Fluoride concentration of fasting whole saliva has been reported to be $0.01-0.05 \mu \mathrm{g} / \mathrm{mL}$, which would increase after eating/drinking or brushing with $\mathrm{F}$ dentifrices or $\mathrm{F}$ topical application. Elevated $\mathrm{F}$ concentrations in non-fasting whole saliva have ranged from 30 minutes after ingestion of optimally fluoridated water to two weeks after topical F application [Duckworth and Morgan, 1991; Duckworth et al., 1987; Ericsson, 1969; Yao and Gron, 1970]. Studies on adults have demonstrated significantly higher F concentrations in whole saliva in subjects receiving fluoridated water $(1-1.2 \mathrm{mg} / \mathrm{L})$ than in those receiving non-fluoridated water $(<0.1 \mathrm{mg} / \mathrm{L})$ proportional to the corresponding fluoride concentrations in plasma [Oliveby et al., 1990; Yao and Gron, 1970]. In adults, Oliveby et al. (1989) also reported that F concentration in whole saliva mirrored that in plasma after ingestion of $1 \mathrm{mg}$ of sodium fluoride. However, whole saliva F concentrations were reported to be unrelated to those in plasma in 5- to 10-year-old children [Whitford et al., 1999]. The latter authors concluded that whole salivary F concentration was not an appropriate marker of plasma F concentration in children due to a fairly large within-mouth pool of $\mathrm{F}$, associated with oral soft tissues/bacteria and dental plaque.

A study that investigated the sensitivity of fingernails to detect $F$ exposure from dentifrice in 1-3 years old children concluded that fingernails might not be a reliable biomarker of fluoride body burden [LimaArsati et al., 2010]. On the other hand, F concentration of toenails has been reported to be positively correlated with $\mathrm{F}$ intake in 4-12 years old children and 25-50 years old females [Linhares et al., 2016]. Pessan and Buzalaf (2011) proposed both finger- and toe-nails as potential biomarkers for monitoring acute, sub-chronic and chronic exposure to F. However, these authors preferred toenails to fingernails as a biomarker due to them being less prone to external F contamination. In the present study, a strong 
correlation was found between toenail F concentration and TDFI; whereas the correlation between

2 fingernail $\mathrm{F}$ concentration and TDFI was moderate. In children, toenails have been reported to grow 3 marginally slower than fingernails; 4.4 vs $4.6 \mathrm{~mm} / \mathrm{month}$ [Fukushima et al., 2009], and therefore toenail clippings may reflect a slightly longer exposure time.

In the present study, hair showed the weakest correlation with $\mathrm{F}$ exposure, indicating hair as a poor biomarker of F exposure. Several studies [Kono et al., 1993; Kono et al., 1990; Mandinic et al., 2010; Schamschula et al., 1988] have reported a positive correlation between F concentration of water and hair. A positive linear correlation between the $\mathrm{F}$ levels in hair and incidence of dental fluorosis has also been reported in 34-60-year-olds [Joshi and Ajithkrishnan, 2018] and in 12-year-old schoolchildren [Mandinic et al., 2010]. In these studies, systemic $\mathrm{F}$ ingestion was not measured, only the $\mathrm{F}$ concentration of the water. Since both nails and hair are prone to external contamination, a decontamination procedure is essential before undertaking $\mathrm{F}$ analysis. The suggested decontamination methods, such as using an interdental brush and sonication using an ultrasound bath, are practical for nail samples but not for hair samples. Due to methodological issues regarding decontamination of hair samples, it is a challenge to clearly distinguish incorporated $\mathrm{F}$ into hair during formation (endogenous) from that which becomes associated with hair following exposure to the environment (exogenous). In addition, some externally deposited trace elements tend to be incorporated into hair and may then be regarded as endogenous [Ophaug, 1994]. Therefore, systematic studies of decontamination procedures are needed to determine the optimum conditions for removing exogenous $\mathrm{F}$ from hair, while retaining endogenous $\mathrm{F}$. The other limiting factors for utilisation of hair as a biomarker are the sampling technique and the required quantity: hair needs to be sampled as close to the scalp as possible, from a relatively large area, to obtain enough for analysis, which may not be accepted by some subjects.

\section{Study limitations:}

Two main limitations of this study are the narrow age group of children, and inclusion of only two F areas (low and high), which were mainly due to time constraints and budget restrictions. The study focused only on 4-5-year olds, due to being able to control their urination and cooperate in this type of investigation. However, this age group is still consistent with the window of susceptibility for fluorosis development in permanent anterior teeth: the first five years of life [O'Mullane et al., 2016]. Although an optimally fluoridated area was not included in the present study, the TDFI showed a wide range from 0.01 to $0.82 \mathrm{mg} / \mathrm{kgbw} / \mathrm{d}$ (Figure 1$)$, covering the optimal $\mathrm{F}$ intake range $(0.05-0.07 \mathrm{mgF} / \mathrm{kgbw} / \mathrm{d})$ with $23 \%$ of children receiving $\mathrm{F}$ at optimal levels.

Since the peak plasma and bone F concentrations are directly related to both the age of the individual and fluoride intake, any extrapolation of the study findings to other age groups should be made with caution. Another limitation is that the samples and data were collected at a single time point for each 
1 individual and consequently missed any possible within-individual variations in $\mathrm{F}$ concentrations of 2 biomarkers. However, since the overall sample and data collections took 4 months, the results cover 3 any possible within-community variations.

4 Although all samples were collected at the same time point for each individual child, the $\mathrm{F}$ 5 concentrations in nail-clippings and hair are directly related to the average $\mathrm{F}$ intake and plasma $\mathrm{F}$ 6 concentration during the period when the nails/hair were formed and not to the exposure that occurred 7 during the day of sampling. Moreover, there was no intervention in the daily routine or dietary habits 8 over the 4 months prior to data collection. In addition, due to the limited variety of consumed diet and 9 toothpaste by the children in this study, it can be assumed that the variation in $\mathrm{F}$ exposure was minimal within the two subject groups.

In conclusion, assessment of $\mathrm{F}$ exposure is a major challenge in interventions to optimise the exposure.

12 The current study confirmed the suitability of $24 \mathrm{~h}$ urine samples for estimating F exposure in children.

13 The strong correlations between TDFI and F in plasma and toenails also suggest these biomarkers may 14 be considered as predictors of $\mathrm{F}$ intake in children. However, the moderate correlation found between 15 TDFI and both fingernail and fasting whole saliva F concentration implies that the F concentrations of 16 these biomarkers might be affected by not only $\mathrm{F}$ intake but also other variables. The poor correlation 17 between $\mathrm{F}$ intake and hair $\mathrm{F}$ concentration suggests that hair may be an unreliable biomarker of $\mathrm{F}$ exposure due to the possible influence of other external factors (e.g. environmental contamination) on its endogenous F content.

The research on various potential health effects of $\mathrm{F}$ requires validation of $\mathrm{F}$ exposure through welldesigned and well-conducted population-based studies. As such, the current study provides new information on the use of $\mathrm{F}$ biomarkers that could help to assess $\mathrm{F}$ exposure and consequently help to inform intervention and policy decision-making to minimise any potential adverse effects of excessive F exposure. 


\section{Acknowledgement}

2 The authors thank Professor Greg Atkinson for his support with statistical analysis. We appreciate the 3 nurse and interpreters who assisted with the field work as well as all the volunteers who participated 4 in the project.

5

\section{Authors' Contributions}

7 FVZ, OSI conceived and designed the study; OSI collected and analysed the samples; FVZ supervised 8 the project with help from RMD and RAV; FVZ and OSI analysed the data and RMD and RAV 9 contributed to the interpretation of the results; FVZ and RMD took the lead in writing the manuscript. 10 All authors read, provided critical feedback and approved the submitted paper.

11 The authors have no conflicts of interest to disclose. 


\section{LEGENDS TO TABLES AND FIGURES}

2

3

4

5

6

7

8

9

10

Table 1. Mean (SD) fluoride exposure and F concentration of biomarkers, stratified by water F area

Figure 1. Relationship between total daily F intake (TDFI) and 24h urinary F excretion (24h UFE) in children ( $\mathrm{n}=56)$.

24h UFE $(\mathrm{mg} / \mathrm{kgbw} / \mathrm{d})=-0.010+[0.648 \times \mathrm{TDFI}(\mathrm{mg} / \mathrm{kgbw} / \mathrm{d})] ; \rho=0.756 ; \mathrm{p}<0.001$

Figure 2. Relationship between total daily F intake (TDFI) and i) plasma (n=60, "o, ") and ii) saliva $(\mathrm{n}=55, " \mathrm{\Delta}$, .") F concentration in children.

Plasma $\mathrm{F}(\mu \mathrm{g} / \mathrm{mL})=0.026+[0.267 \times$ TDFI $(\mathrm{mg} / \mathrm{kgbw} / \mathrm{d})] ; \rho=0.770 ; \mathrm{p}<0.001$

Saliva $\mathrm{F}(\mu \mathrm{g} / \mathrm{mL})=0.020+[0.224 \times$ TDFI $(\mathrm{mg} / \mathrm{kgbw} / \mathrm{d})] ; \rho=0.453 ; \mathrm{p}=0.001$

Figure 3. Relationship between total daily F intake (TDFI) and i) finger-nail ( $n=43$, “o, ...."), and ii) toe-nail ( $\mathrm{n}=51$, “ $\mathrm{x}$, - - - ") F concentration in children.

Fingernail $\mathrm{F}(\mu \mathrm{g} / \mathrm{g})=4.439+[12.854 \times \mathrm{TDFI}(\mathrm{mg} / \mathrm{kgbw} / \mathrm{d})] ; \rho=0.470 ; \mathrm{p}<0.001$

Toenail F $(\mu \mathrm{g} / \mathrm{g})=3.758+[16.703 \times \mathrm{TDFI}(\mathrm{mg} / \mathrm{kgbw} / \mathrm{d})] ; \rho=0.604 ; \mathrm{p}<0.001$

Figure 4. Relationship between total daily F intake (TDFI) and hair F concentration in children ( $\mathrm{n}=52)$.

Hair F $(\mu \mathrm{g} / \mathrm{g})=0.94+[1.860 \times$ TDFI $(\mathrm{mg} / \mathrm{kgbw} / \mathrm{d})] ; \rho=0.306 ; \mathrm{p}=0.027$ 


\section{REFERENCES}

Boros I, Keszler P, Banoczy J: Fluoride concentrations of unstimulated whole and labial gland saliva in young adults after fluoride intake with milk. Caries

Rese 2001;35:167-172.

Burt BA: The changing patterns of systemic fluoride intake. J Dent Res 1992;71:1228-1237.

Buzalaf MA, Whitford GM: Fluoride Metabolism; in Buzalaf MA (ed): Fluoride and the Oral Environment. Monographs in Oral Sciecne. Basel, Switzerlan, Karger, 2011.

Buzalaf MAR, Massaro CS, Rodrigues MHC, Fukushima R, Pessan JP, Whitford GM, Sampaio FC: Validation of fingernail fluoride concentration as a predictor of risk for dental fluorosis. Caries Res 2012;46:394-400.

Buzalaf MAR, Rodrigues MHC, Pessan JP, Leite AL, Arana A, Villena RS, Forte FDS, Sampaio FC: Biomarkers of Fluoride in Children Exposed to Different Sources of Systemic Fluoride. J Dent Res 2011;90:215.

Czarnowski W, Krechniak J: Fluoride in the urine, hair, and nails of phosphate fertiliser workers. Br J Ind Med 1990;47:349-351.

Duckworth RM, Morgan SN: Oral fluoride retention after use of fluoride dentifrices. Caries Res 1991;25:123-129.

Duckworth RM, Morgan SN, Murray AM: Fluoride in Saliva and Plaque Following Use of Fluoride-Containing Mouthwashes. J Dent Res 1987;66:17301734.

Ekstrand J, Fomon SJ, Ziegler EE, Nelson SE: Fluoride pharmacokinetics in infancy. Pediatr Res 1994;35:157-163.

Ericsson Y: Fluoride excretion in human saliva and milk. Caries Res 1969;3:159-166. 
Evan J: Straightforward statistics for the behavioral sciences in: Percept Mot Skills. Pacific Grove, California, Brooks/Cole Publishing, 1996.

Fukushima R, Rigolizzo DS, Maia LP, Sampaio FC, Lauris JR, Buzalaf MA, Fukushima R, Rigolizzo DS, Maia LP, Sampaio FC, Lauris JRP, Buzalaf MAR: Environmental and individual factors associated with nail fluoride concentration. Caries Res 2009;43:147-154.

GBD 2016 Risk Factors Collaborator: GBD 2016 Risk Factors Collaborators. Global, regional, and national comparative risk assessment of 84 behavioural, environmental and occupational, and metabolic risks or clusters of risks, 1990-2016: a systematic analysis for the Global Burden of Disease Study 2016 (vol 390, pg 1343, 2017). Lancet 2017;390:1736-1736.

Harding MA, O'Mullane DM: Water fluoridation and oral health. Acta Med Acad 2013;42:131-139.

Hellwig E, Lennon AM: Systemic versus topical fluoride. Caries Res 2004;38:258-262.

Ibiyemi O, Zohoori FV, Valentine RA, Maguire A: Fluoride intake and urinary fluoride excretion in 4-and 8-year-old children living in urban and rural areas of Southwest Nigeria. Community Dent Oral Epidemiol 2018;46:482-491.

Idowu O: Biomarkers of fluoride exposure in children and adults; in: School of Health and Social Care. Middlesbrough, Teesside University, 2018, vol PhD.

Joshi NA, Ajithkrishnan CG: Scalp Hair as Biomarker for Chronic Fluoride Exposure among Fluoride Endemic and Low Fluoride Areas: A Comparative Study. Int J Trichology 2018;10:71-75.

Khan A, Moola MH, Cleaton-Jones P: Global trends in dental fluorosis from 1980 to 2000: a systematic review. SADJ 2005;60:418-421.

Kono K, Yoshida Y, Watanabe M, Orita Y, Dote T, Bessho Y: Urine, serum and hair monitoring of hydrofluoric acid workers. Int Arch Occup Environ Health 1993;65:S95-98. 
Kono K, Yoshida Y, Watanabe M, Watanabe H, Inoue S, Murao M, Doi K: Elemental analysis of hair among hydrofluoric acid exposed workers. Int Arch Occup Environ Health 1990;62:85-88.

Levy FM, Bastos JR, Buzalaf MA, Levy FM, Bastos JRdM, Buzalaf MAR: Nails as biomarkers of fluoride in children of fluoridated communities. Journal of Dentistry for Children (Chicago, Ill ) 2004;71:121-125.

Levy SM, Zarei-M Z: Evaluation of fluoride exposures in children. J Dent Child 1991;58:467-473.

Lima-Arsati YB, Martins CC, Rocha LA, Cury JA: Fingernail may not be a reliable biomarker of fluoride body burden from dentifrice. Braz Dent J 2010;21:91-97.

Limon-Pacheco JH, Jimenez-Cordova MI, Cardenas-Gonzalez M, Sanchez Retana IM, Gonsebatt ME, Del Razo LM: Potential Co-exposure to Arsenic and Fluoride and Biomonitoring Equivalents for Mexican Children. Ann Glob Health 2018;84:257-273.

Linhares DPS, Garcia PV, Amaral L, Ferreira T, Cury JA, Vieira W, Rodrigues AD: Sensitivity of two biomarkers for biomonitoring exposure to fluoride in children and women: A study in a volcanic area. Chemosphere 2016;155:614-620.

Mandinic Z, Curcic M, Antonijevic B, Carevic M, Mandic J, Djukic-Cosic D, Lekic CP: Fluoride in drinking water and dental fluorosis. Sci Total Environ 2010;408:3507-3512.

Martínez-Mier EA, Cury J.A., Heilman J.R. , Katz B.P., Levy S.M., Li Y., Maguire A., Margineda J., O’Mullane D., Phantumvanit P., Soto-Rojas A.E., Stookey G.K., Villa A., Wefel J.S., Whelton H., Whitford G.M., Zero D.T., Zhang W., Zohouri V: Development of gold standard ion-selective electrodebased methods for fluoride analysis Caries Res 2011;45:3-12.

Martinez-Mier EA, Soto-Rojas AE, Urena-Cirett JL, Stookey GK, Dunipace AJ: Fluoride intake from foods, beverages and dentifrice by children in Mexico. Community Dent Oral Epidemiol 2003;31:221-230. 
O'Mullane DM, Baez RJ, Jones S, Lennon MA, Petersen PE, Rugg-Gunn AJ, Whelton H, Whitford GM: Fluoride and Oral Health. Community Dent Health 2016;33:69-99.

Oliveby A, Lagerlof F, Ekstrand J, Dawes C: Studies on fluoride excretion in human whole saliva and its relation to flow rate and plasma fluoride levels. Caries Res 1989;23:243-246.

Oliveby A, Twetman S, Ekstrand J: Diurnal fluoride concentration in whole saliva in children living in a high- and a low-fluoride area. Caries Res 1990;24:44-47.

Ophaug R: Determination of fluorine in biological materials: reaction paper. Adv Dent Res 1994;8:87-91.

Pessan JP, Buzalaf MRA: Historical and Recent Biological Markers of Exposure to Fluoride. Monogr Oral Sci 2011;22:52-65.

Rugg-Gunn AJ, Villa AE, Buzalaf MRA: Contemporary biological markers of exposure to fluoride. Monogr Oral Sci. 2011; 22, 37-51.

Schamschula RG, Duppenthaler JL, Sugar E, Un PS, Toth K, Barmes DE: Fluoride intake and utilization by Hungarian children: associations and interrelationships. Acta Physiol Hung 1988;72:253-261.

Schamschula RG, Sugar E, Un PS, Toth K, Barmes DE, Adkins BL: Physiological indicators of fluoride exposure and utilization: an epidemiological study. Community Dent Oral Epidemiol 1985;13:104-107.

Thomas DB, Basu N, Martinez-Mier EA, Sanchez BN, Zhang ZZ, Liu Y, Parajuli RP, Peterson K, Mercado-Garcia A, Bashash M, Hernandez-Avila M, Hu H, Tellez-Rojo MM: Urinary and plasma fluoride levels in pregnant women from Mexico City. Environ Res 2016;150:489-495.

Villa A, Anabalon M, Zohouri V, Maguire A, Franco AM, Rugg-Gunn A: Relationships between fluoride intake, urinary fluoride excretion and fluoride retention in children and adults: an analysis of available data. Caries Res 2010;44:60-68. 
Whitford GM: Monitoring fluoride exposure with fingernail clippings. Schweizer Monatsschrift fur Zahnmedizin 2005;115:685-689.

Whitford GM, Thomas JE, Adair SM: Fluoride in whole saliva, parotid ductal saliva and plasma in children. Arch Oral Biol 1999;44:785-788.

World Health Organization: Fluorides and oral health. Report of a WHO Expert Committee on Oral Health Status and Fluoride Use; Geneva, Switzerland, 1994.

World Health Organization: Basic methods for assessing renal fluoride excretion in community prevention programmes for oral health; Geneva, Switzerland, 2014.

Yao K, Gron P: Fluoride concentration in duct saliva and whole saliva. Caries Res 1970;4:321-331.

Zipkin I, Linkins R, McClure F, Steere A: Urinary fluoride levels associated with the use of fluoridated drinking water. Public Health Rep 1956;71:762-772.

Zohoori FV: Summary of General Discussion and Conclusions. Adv Dent Res 2018;29:183-185.

Zohoori FV, Duckworth RM, Omid N, O'Hare WT, Maguire A: Fluoridated toothpaste: usage and ingestion of fluoride by 4- to 6-yr-old children in England. Eur J Oral Sci 2012;120:415-421.

Zohoori FV, Maguire A: Determining an upper reference value for the urinary fluoride-creatinine ratio in healthy children younger than 7 years. Caries Res 2017;51:283-289.

Zohouri FV, Rugg-Gunn AJ: Sources of dietary fluoride intake in 4-year-old children residing in low, medium and high fluoride areas in Iran. Int J Food Sci Nutr 2000;51:317-326. 
Zohouri FV, Swinbank CM, Maguire A, Moynihan PJ: Is the fluoride/creatinine ratio of a spot urine sample indicative of 24-h urinary fluoride? Community Dent Oral Epidemiol 2006;34:130-138. 
Table 1. Mean (SD) fluoride exposure and F concentration of biomarkers, stratified by water F area

\begin{tabular}{|c|c|c|c|c|}
\hline \multirow[b]{2}{*}{ Parameters } & \multicolumn{2}{|l|}{ F water area } & \multirow{2}{*}{$\begin{array}{l}\text { Mean difference } \\
(95 \% \mathrm{CI})\end{array}$} & \multirow[b]{2}{*}{$\mathrm{p}$-value } \\
\hline & $\begin{array}{l}\text { Low } \\
(0.04 \mathrm{mg} \mathrm{F} / \mathrm{L})\end{array}$ & $\begin{array}{l}\text { High } \\
\text { (3.05 mg F/L) }\end{array}$ & & \\
\hline \multicolumn{5}{|l|}{ Daily F intake (mg/kgbw/d) from: } \\
\hline Toothpaste ingestion & $0.014(0.008)$ & $0.014(0.160)$ & $0.000(-0.007,+0.008)$ & 0.900 \\
\hline Diet & $0.060(0.038)$ & $0.266(0.183)$ & $-0.205(-0.134,-0.276)$ & $<0.001$ \\
\hline Total daily $\mathrm{F}$ intake (TDFI) & $0.075(0.036)$ & $0.277(0.184)$ & $-0.202(-0.131,-0.273)$ & $<0.001$ \\
\hline Urinary F concentration $(\mu \mathrm{g} / \mathrm{mL})$ & $0.175(0.111)$ & $5.696(3.075)$ & $-5.521(-6.691,-4.350)$ & $<0.001$ \\
\hline $24 \mathrm{~h}$ urinary $\mathrm{F}$ excretion $(\mathrm{mg} / \mathrm{kgbw} / \mathrm{d})$ & $0.004(0.002)$ & $0.210(0.143)$ & $-0.205(-0.261,-0.150)$ & $<0.001$ \\
\hline \multicolumn{5}{|l|}{ F concentration: } \\
\hline Saliva $(\mu \mathrm{g} / \mathrm{mL})$ & $0.008(0.006)$ & $0.098(0.070)$ & $-0.091(-0.116,-0.065)$ & $<0.001$ \\
\hline Plasma $(\mu \mathrm{g} / \mathrm{mL})$ & $0.029(0.011)$ & $0.116(0.051)$ & $-0.087(-0.106,-0.068)$ & $<0.001$ \\
\hline Hair $(\mu \mathrm{g} / \mathrm{g})$ & $0.743(0.609)$ & $1.831(1.091)$ & $-1.088(-1.590,-0.586)$ & $<0.001$ \\
\hline Fingernail $(\mu \mathrm{g} / \mathrm{g})$ & $3.237(2.636)$ & $10.420(3.761)$ & $-6.993(-8.800,-5.186)$ & $<0.001$ \\
\hline Toenail $(\mu \mathrm{g} / \mathrm{g})$ & 3.378 (2.197) & $10.371(3.907)$ & $-7.182(-9.201,-5.218)$ & $<0.001$ \\
\hline
\end{tabular}




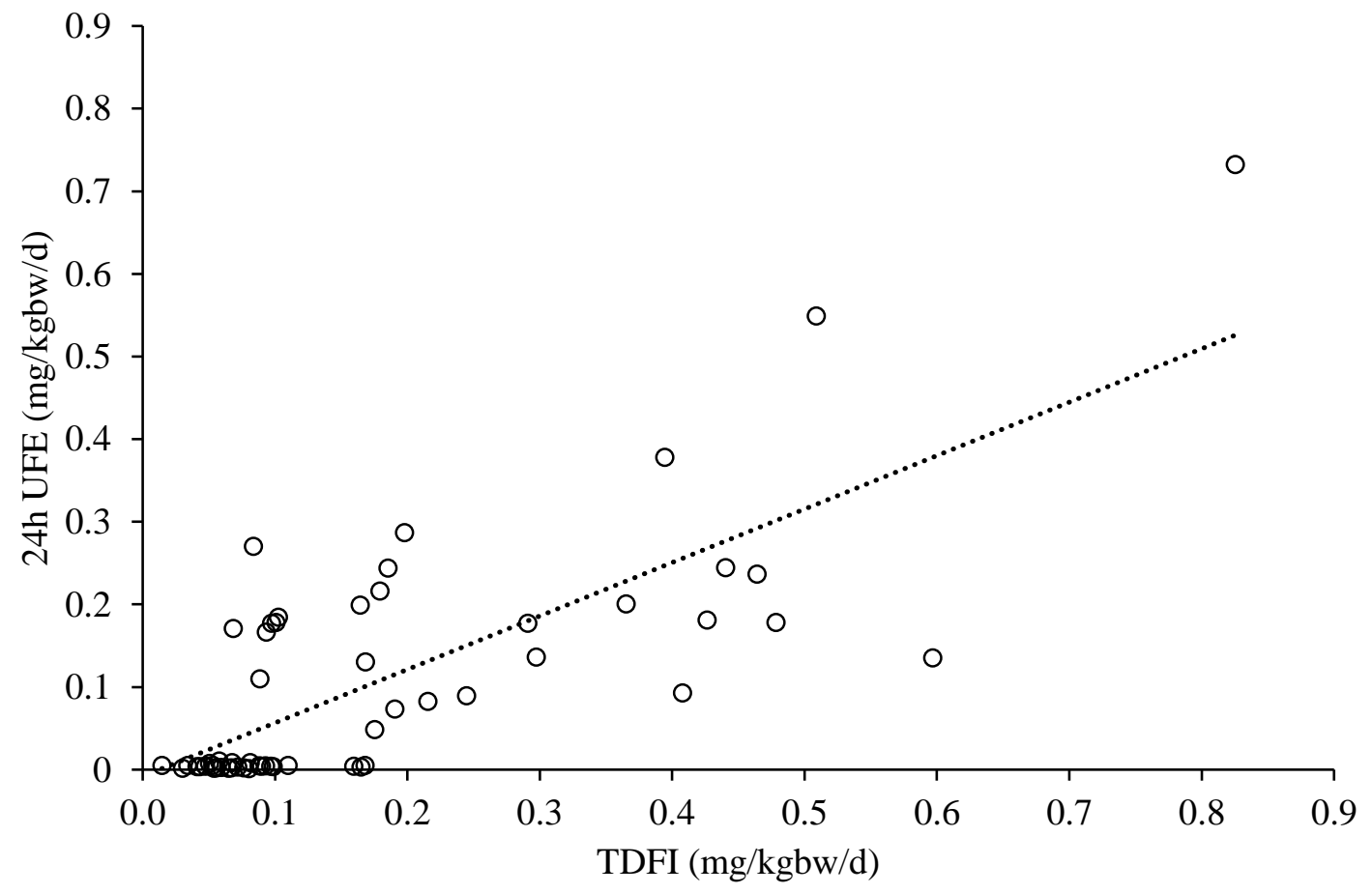

5

6 Figure 1. Relationship between total daily F intake (TDFI) and 24h urinary F excretion (24h UFE) in 7 children $(n=56)$.

$824 \mathrm{~h} \mathrm{UFE}(\mathrm{mg} / \mathrm{kgbw} / \mathrm{d})=-0.010+[0.648 \times \mathrm{TDFI}(\mathrm{mg} / \mathrm{kgbw} / \mathrm{d})] ; \rho=0.756 ; \mathrm{p}<0.001$ 


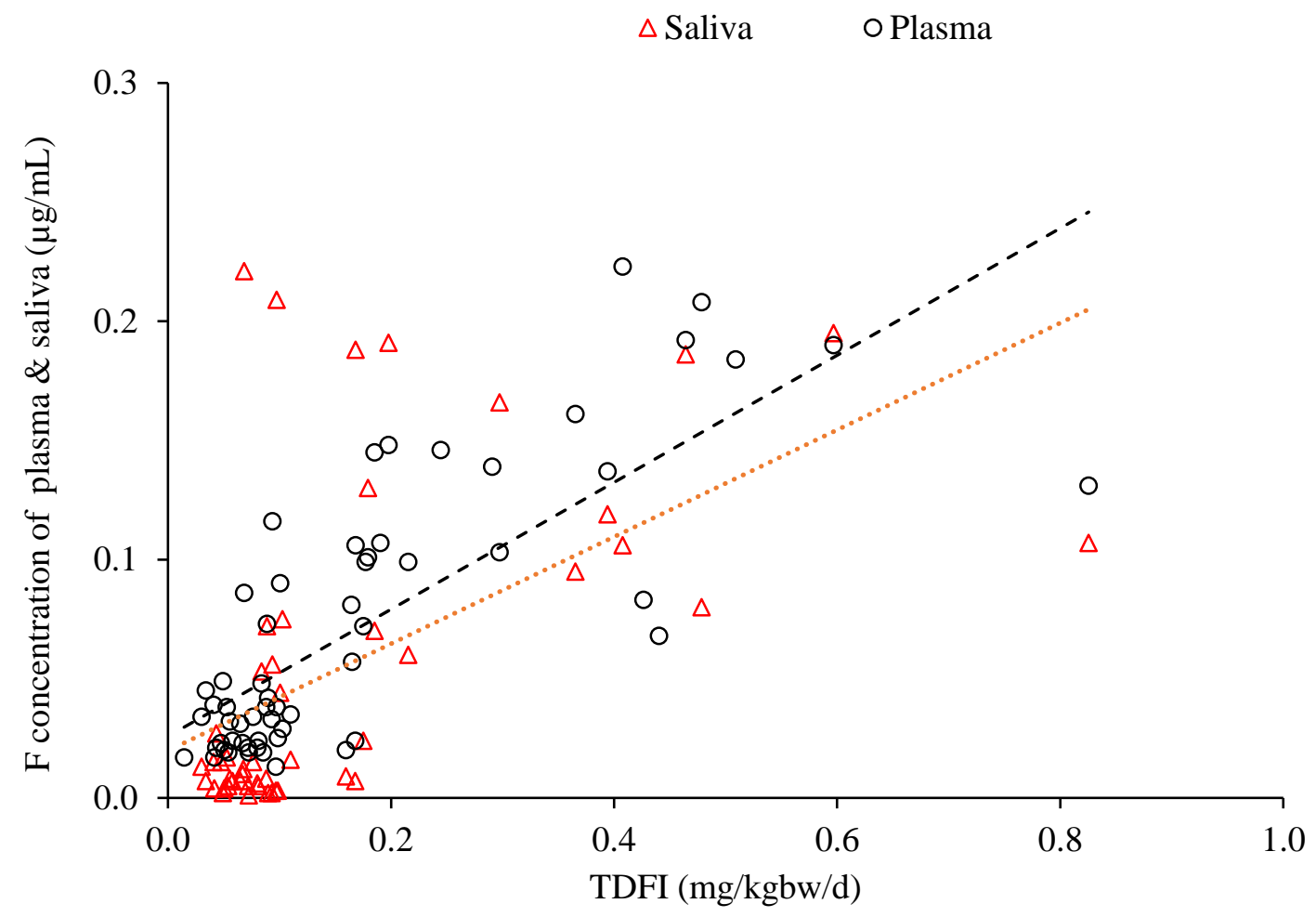

3

4

5 Figure 2. Relationship between total daily F intake (TDFI) and i) plasma (n=60, “o, ") and ii)

6 saliva $(\mathrm{n}=55, " \Delta, \ldots \ldots . .,) \mathrm{F}$ concentration in children.

$7 \quad$ Plasma $\mathrm{F}(\mu \mathrm{g} / \mathrm{mL})=0.026+[0.267 \times$ TDFI $(\mathrm{mg} / \mathrm{kgbw} / \mathrm{d})] ; \rho=0.770 ; \mathrm{p}<0.001$

8 Saliva $\mathrm{F}(\mu \mathrm{g} / \mathrm{mL})=0.020+[0.224 \times \mathrm{TDFI}(\mathrm{mg} / \mathrm{kgbw} / \mathrm{d})] ; \rho=0.453 ; \mathrm{p}=0.001$ 
o Finger-nail $\quad \times$ Toe-nail

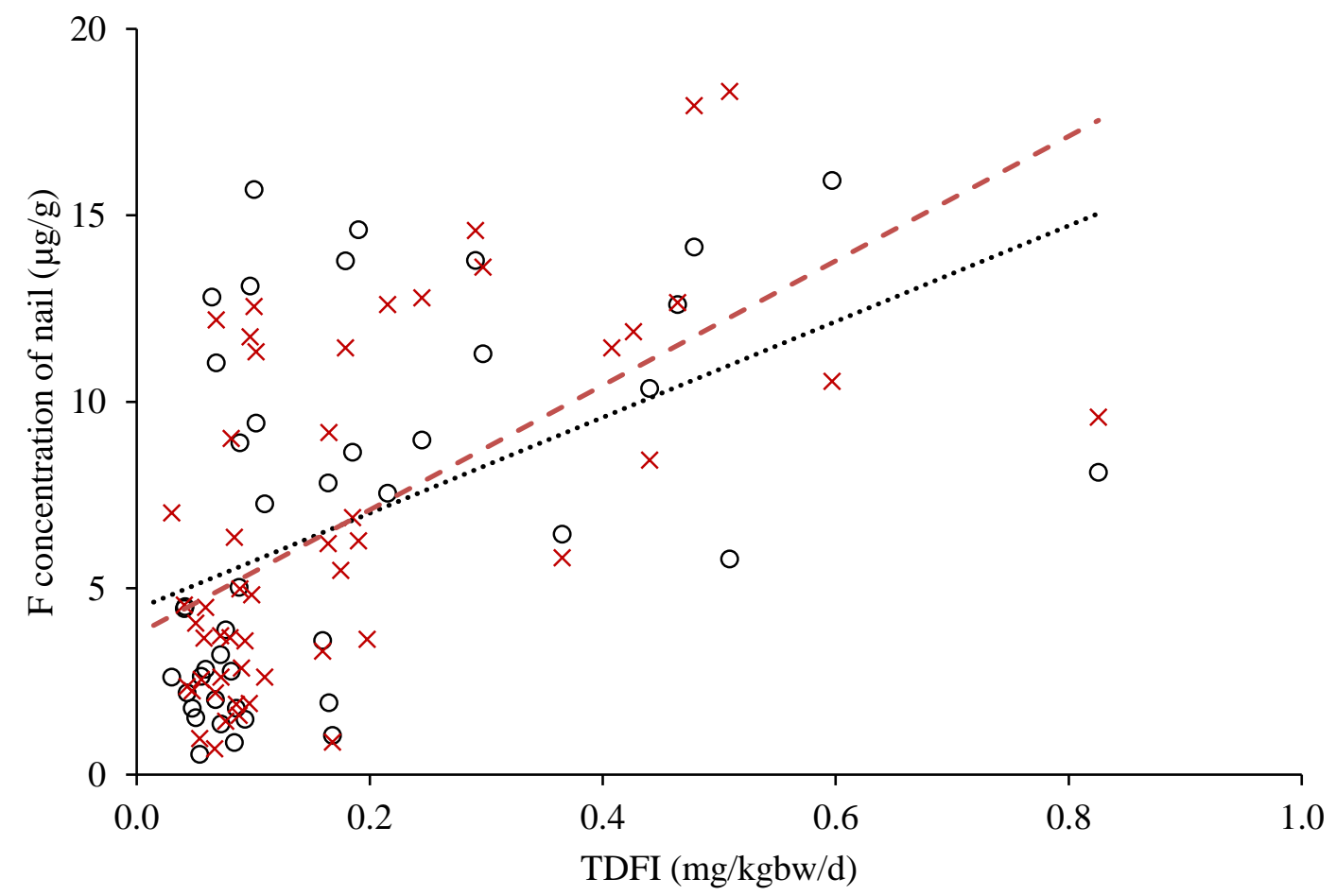

2

3 Figure 3. Relationship between total daily F intake (TDFI) and i) finger-nail (n=43, “o, ...”), and ii)

4 toe-nail (n= 51, “x, - - -") F concentration in children.

$5 \quad$ Fingernail $\mathrm{F}(\mu \mathrm{g} / \mathrm{g})=4.439+[12.854 \times \mathrm{TDFI}(\mathrm{mg} / \mathrm{kgbw} / \mathrm{d})] ; \rho=0.470 ; \mathrm{p}<0.001$

6 Toenail F $(\mu \mathrm{g} / \mathrm{g})=3.758+[16.703 \times \mathrm{TDFI}(\mathrm{mg} / \mathrm{kgbw} / \mathrm{d})] ; \rho=0.604 ; \mathrm{p}<0.001$

7 


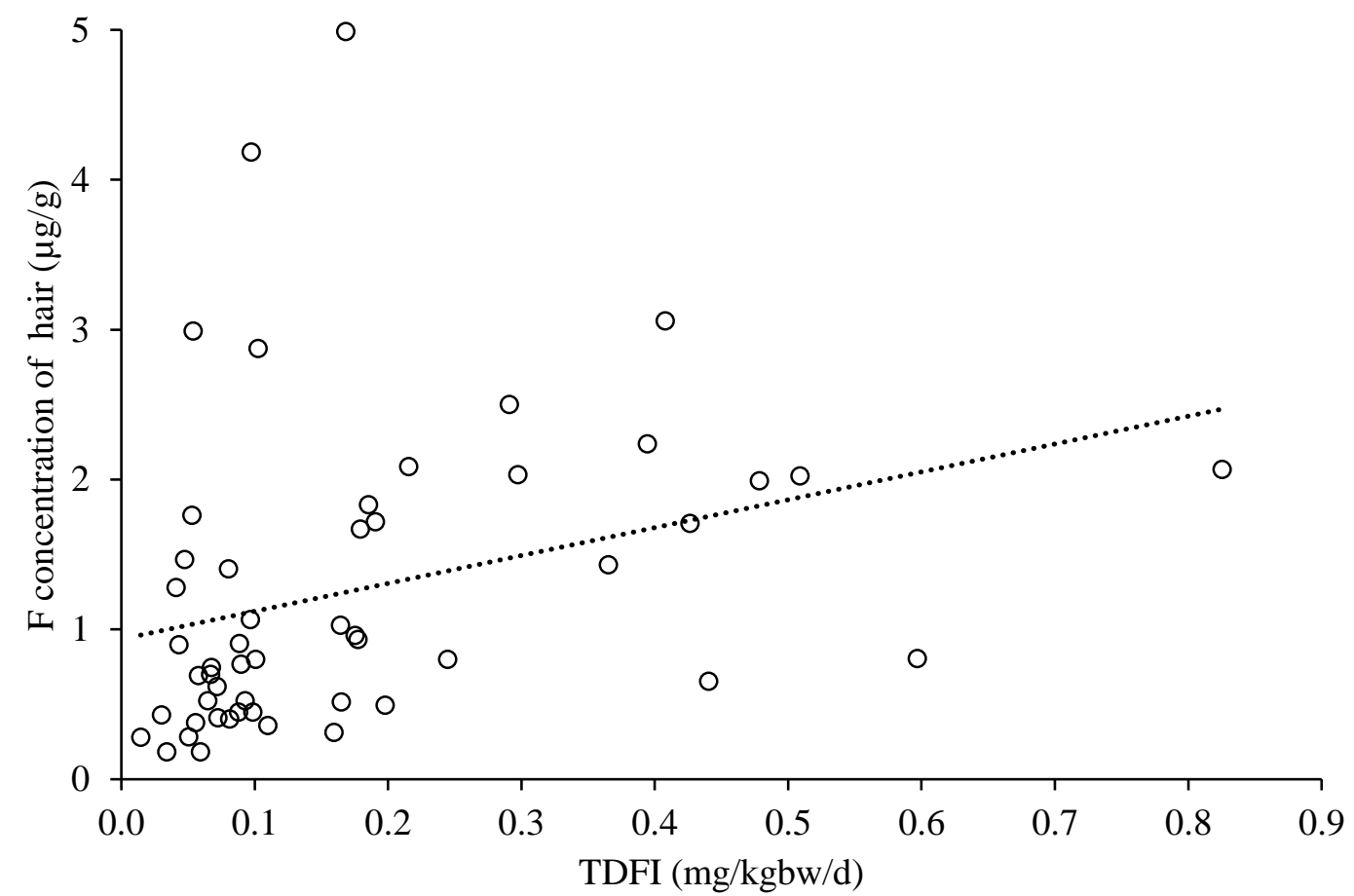

2 Figure 4. Relationship between total daily F intake (TDFI) and hair F concentration in children $3(n=52)$.

$4 \quad$ Hair F $(\mu \mathrm{g} / \mathrm{g})=0.94+[1.860 \times \mathrm{TDFI}(\mathrm{mg} / \mathrm{kgbw} / \mathrm{d})] ; \rho=0.306 ; \mathrm{p}=0.027$ 